\title{
Outsourcing and its impact on operational objectives and performance: a study of Iranian telecommunication industries
}

\author{
Amir Reza Khaki ${ }^{\mathbf{a}^{*}}$ and Sadra Rashidi ${ }^{\mathbf{b}}$
}

${ }^{a}$ Department of Industrial Engineering, Science and Research Branch, Islamic Azad University, Tehran, Iran

${ }^{b}$ Department of Industrial Engineering, Islamic Azad University, Ilam Branch, Ilam, Iran

\section{A R T I C L E I N F O}

Article history:

Received June 18, 2011

Received in Revised form

August, 24, 2011

Accepted 25 August 2011

Available online

27 August 2011

Keywords:

Outsourcing

Productivity

Supply chain management

Efficiency

\section{A B S T R A C T}

Through outsourcing, a company can expand and develop its sources and capacities by accessing to higher quality services and better functionality. This paper deals with the perception of the managers of the telecommunication industry sector on the effects of outsourcing on operational strategy and especially on the issues associated with cost reduction, developed quality, flexibility and better service. Because of the importance of the strategic feature of outsourcing, we examined its effects on the organizational function of the telecommunication industries. This study shows that managers believe that outsourcing has a great impact not only on the cost reduction but also on other goals of operational strategies, which makes outsourcing become inherently more strategic. In addition, it seems that outsourcing influences function noticeably.

In the present research, the relationships between propensity to outsourcing and operational objectives and organizational performance in telecommunication industries are assessed. The aim of this research is to examine the propensity to outsourcing and its impacts on operational objectives including cost reduction, improved quality, flexibility and better service and organizational performance, which includes financial performance and non-financial performance .

In the research, data are collected through field research and questionnaires. The questionnaires are distributed among the board of directors, quality managers, operational administrators, and lower managers and then the feedbacks are analyzed using SPSS and Minitab software based on deductive and descriptive statistics.

(C) 2012 Growing Science Ltd. All rights reserved.

\section{Introduction}

Nowadays, there are many issues such as the augmentation of competitive pressures, business difficulties, limitation of sources, technologic complexities and specialization of tasks, acceleration of environmental changes, uncertainty about future, price increase, excessive enlargement of some organizations and legal considerations, which leads organizations to reconsider their managerial models to reach competitive advantages. One of these strategies is to focus on the core competencies and to entrust most of the activities to out-side suppliers or to outsource them. So in order to obtain

* Corresponding author. Tel: +989181413107

E-mail addresses: amirk28@yahoo.com (A R. Khaki) 
the possibilities to do the tasks and simultaneously to give desirable services to the customers and to enable firms to react to various demands, outsourcing strategy is a necessary tool used by many progressive firms (Frayer et al., 2000; Masaaki et al., 2008).

Most of active companies and firms in Iranian telecommunication industry are small and to keep their competition with their counterpart foreign progressive companies they have to use new and modern technologies. They also need to gain ability to meet the country's increasing needs through reducing costs and increasing flexibility in delivering services and outsourcing is one of the important ways to reach these goals. We try to examine some of these active firms, which are active in the telecommunication industry (telephone, mobile, and data) in order to survey the effects of outsourcing functions and activities on their competitive priorities and organizational functions.

One of the most outstanding features of the new millennium, or information age, is the rapid environmental changes. There is no doubt that this rapid change will affect today's business world, in other words it will revolutionize the traditional business and job paradigms. This volatile and changing atmosphere compels organizations to adapt their structures and strategies to a greater degree than they used to do. Nowadays, organizations trend to become "network-center", in other words to work in a "small core-big network" forms. Thus, companies choose a limited number of tasks to do and entrust the rest of their tasks to an outside supplier. Therefore, the significance of outsourcing and its key role in illustrating network-center organizations is clear. (Frayer et al., 2000)

There are several reasons to believe that organizations attempt to outsource their activities. By justifying that outsourcing decisions are strategic, this strategy can be the source of many fundamental changes in the organization. Therefore, the most important point is to manage these crucial changes, precisely. The other point is that outsourcing does not mean absolve responsibility from an outsourcing organization or buyer. It means to entrust activities to outside organizations or people in order to achieve better efficiency, better responsiveness, and reduction of costs. However, it does not mean to entrust the whole responsibilities (Espino-Rodriguez \& Padron-Robaina, 2004).

\section{Literature review}

The significant level of outsourcing programs used across all business sectors is well documented in the literature (Lau \& Hurly, 1997; Klaas et al., 2001; Steensma \& Corley, 2000; Bardhan \& Kroll, 2008). Past research has progressed along several paths. First, some researchers focused on motivations and reasons for outsourcing activities (Belcourt, 2006; Frayer et al., 2000; White, 2000). According to this perspective, the global imperative for outsourcing accelerates as firms evolve from sellers of products and services abroad to setting up operations in foreign countries and staffing those operations with host countries or third party nationals (Kedia \& Lahiri, 2007). Most corporations believe that in order to compete globally, they must look at efficiency and cost containment rather than relying strictly on revenue increases. As companies look for enhancing their competitive positions in an increasingly global marketplace, they discover that they can cut costs and maintain quality by relying more on outside service providers for activities viewed as supplementary to their core businesses (Li et al., 2006).

Other researchers have identified several outsourcing issues, trends and strategies that companies take in establishing and effectively managing their outsourcing activities. The trend is for outsourcing relationships to function more as partnerships. Outsourcing providers are taking increasing responsibility in realms that have traditionally remained in-house, such as corporate strategy, information management, business investment, and internal quality initiatives (Duncan \& GrovesRowan, 1997). A survey of U.S. CEO's shows that 42 percent of communication firms, 40 percent of computer manufactures, and 37 percent of semiconductor companies rely on global outsourcing. According to another survey conducted by Duncan and Groves-Rowan (1997), more than 65 percent of banks surveyed revealed that they were involved in at least one type of outsourcing function. "The 
five most commonly used outsourcing functions in banking were taxes, bankruptcy/foreclosures, systems, cashiering, and insurance". Personnel expenses were the primary reasons behind banking outsourcing; however, it also improves operating efficiency and reduces service costs (Klass et al., 2001).

On the other hand, Kotabe (1998) suggested that there could be some negative long-term consequences of outsourcing resulting from a company's dependence on independent suppliers. Such reliance on outsourcing may make it difficult for the company to sustain its long-term competitive advantages without engaging in the developmental activities of the constantly evolving design and engineering technologies. There are other investigations, which indicate that the outcomes of technology-sourcing partnerships from the sourcing firms' point of view were more effective than contract-based outsourcing (Steensma \& Corley, 2000). Steensma and Corley (2000) suggested that the outcomes from technology partnerships for sourcing firms depend on the interaction between technology attributes and the interdependence between source and sourcing firms. Other researchers also focused on outsourcing strategy effectiveness and its impact on organizational characteristics.

Frayer et al. (2001) suggested that in order for an out-sourcing strategy to work effectively, companies must proactively manage their outsourcing strategies by establishing top management commitment, global sourcing structures and processes, and global sourcing business capabilities. In addition, they suggested that companies that have not raised their sourcing approach to global, strategic level might already be behind in terms of quality, cost, delivery, technology, performance, and customer service. Klaas et al. (2001), suggested that the influence of organizational characteristics was highly contingent, suggesting that organizational characteristics have different effects on various types of outsourcing activities outsourced. As such, it appears that many factors such as pay level, promotional opportunities and demand uncertainty should be considered when deciding to outsource functions or activities.

Other researchers have focused on outsourcing performance measures (Kotabe, 2008; Choi, 2008). For example, Kotabe (1998) identified three types of performance measures as necessary components in any outsourcing performance measurement system: strategic measures; financial measures; and quality measures. Other studies use additional dimensions of market performance such as costs savings, cycle time, customer satisfaction, and productivity to measure the effectiveness of outsourcing strategy (Kotabe, 2008). From a different perspective, obstacles such as poor choices of sourcing partners, inadequate planning and training/skills needed to manage outsourcing activities and poor organizational communication have also been identified as impacting the success of outsourcing projects.

How is successful outsourcing performed? Literature identifies high-level approaches to outsourcing, but not detailed methodologies. Furthermore, there is a little empirical research investigating outsourcing performance implications (Agrawal et al., 2006). Additionally, while consultants identify the success of their approach, they do not identify the failures or problems of their approach as readily. Fewer studies have examined the outcomes of outsourcing activities. Lau and Hurley (1997) found a significant relationship between outsourcing and profitability margin where they found that Chrysler's profit margin was four times as high as that of GM due to effective outsourcing through strategic alliances. Frayer et al. (2000) reported that companies are increasingly viewing outsourcing strategies as a means of reducing costs, increasing quality, and enhancing a firm's overall competitive position.

The literature of this research, especially those related to Iran's Telecommunication Industry does not have any experimental investigation to analyze the effects of outsourcing on the strategic goals and 
organizational functions. The main objective of this research is to consider strategic goals and organizational functions, simultaneously.

\section{Definitions and concepts}

There are numerous definitions for outsourcing. Here is one of its general definitions: Entrusting some of the in-house recurrent activities and decision making options to outside contractors through a contract or a letter of intent. This means that not only the activities are entrusted but also factors of production and decision making options are entrusted. According to Frayer et al. (2000), the main constituent elements of outsourcing are as follows.

- Buyer (an organization or a person who entrusts a service)

- Supplier (provider of a service)

- The thing which is outsourced

\subsection{The advantages of outsourcing}

Although the definition of outsourcing has been somewhat uncertain, many potential benefits of outsourcing have been identified in the literature. Those most often discussed are:

- Improved financial performance (attributable, in part, to almost immediate cost improvements),

- Various non-financial performance effects, such as a heightened focus on core competencies,

- Cost reduction,

- Reduction of manufacturing costs and investment in plant and equipment. (This reduced investment in manufacturing capacity lowers fixed costs and leads to a lower break-even point),

- The short-run cost improvement,

- In-house production increases organizational commitment,

- Quick response to changes in the environment,

- Increase managerial attention and resource allocation to those tasks that it does best and to rely on management teams in other organizations to oversee tasks at which the outsourcing firm is at a relative disadvantage,

- To promote competition among outside suppliers, thereby ensuring availability of higherquality goods and services in the future.

The importance of defining and developing the core competence of the firm has attained great popularity among management researchers and practitioners. This has increasingly led to a move away from market-based definitions of businesses toward more competence-based definitions.

\subsection{The disadvantages of outsourcing}

- Loss of overall market performance,

- Declining innovation by the outsourcer,

- Lose touch with new technological breakthroughs,

- As suppliers gain knowledge of the product being manufactured, they may use that knowledge to begin marketing the product on their own.

- Tariffs are another danger associated with outsourcing,

- Difficulty of bringing back into the firm activities,

\subsection{The reasons for outsourcing and expected advantages}

Organizations use outsourcing for several reasons. It is not surprising that different organizations for different purposes use outsourcing; because every organization's condition is unique and it differs 
from other organizations'. According to Li et al. (2006) some of the reasons organizations use outsourcing are as follows,

- To develop and focus on fundamental functions,

- To access the world-class abilities and facilities,

- Long-term flexibility,

- The acceleration of reengineering advantages,

- To increase sections and functions (evolution and change in the organization),

- To have a perfect to the best experiments and to achieve new skills,

- To access to new services,

- To reduce the costs and the overall price of the products by finding suppliers who have better functions and lower cost structures,

- To create or increase liquidity.

\section{The proposed model}

The present study is both a field and inferential research. Field studies are a kind of non-experimental scientific surveys where the goal is to discover the relationship between actual variables. On the other hand, this study is referential because it expands the results from the sample to the population. Since we can use the results in industrial companies, it can be said that according to its goal it is a practical research.

\subsection{Analytical model of the research}

In this research, we surveyed more than 38 active companies in the field of telecommunication equipment production in Iran. We considered control variables such as similarity between activities and productions, activity records and outsourcing records, and to gain exact results we chose 12 companies as the ultimate statistical population. The analytical model used here is like the following figure. The functional-goal variables are cost reduction, quality improvement, flexibility and service. The dimensions of organizational function include financial and non-financial function.

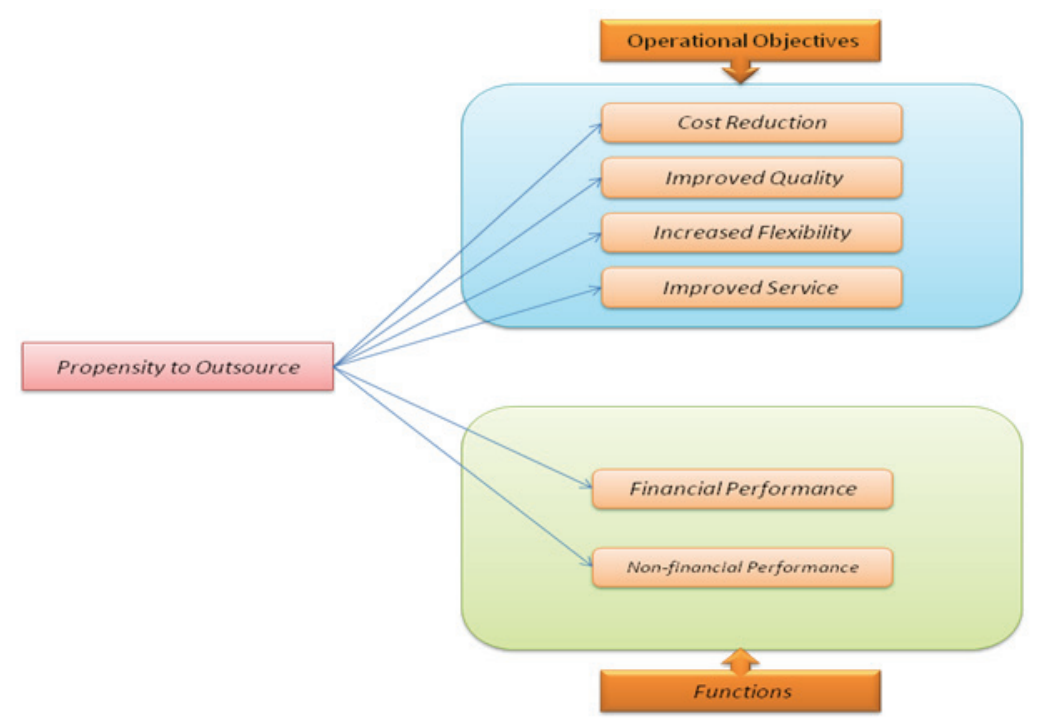

Fig.1. Analytical model 


\subsection{The hypotheses}

H1: the propensity to outsource operations and activities exerts a positive influence on the operations objective "improved service".

$\mathrm{H} 2$ : the propensity to outsource operations and activities exerts a positive influence on the operations objective "cost reduction".

H3: the propensity to outsource operations and activities exerts a positive influence on the operations objective "improved quality".

H4: the propensity to outsource operations and activities exerts a positive influence on the operations objective "flexibility".

H5: improved organizational function is directly associated with outsourcing.

\subsection{Statistical population}

Most of active companies and firms in our telecommunication industry are small and in order to keep their competition with their counterpart foreign progressive, they have to use new and modern technologies and gain ability to meet the country's increasing needs to reduce costs and to increase flexibility in delivering services, access to the new technologies, etc. Outsourcing is one of the important ways, where these firms can use. Because $\mathrm{N}=130$, we used Krejcie and Morgan table and gained a sample volume of 97. So we passed out 97 questionnaires (statistical population includes 130 senior managers, functional managers, control managers, and supplier managers such as logistic managers) and then the filled out forms collected.

\subsection{Data analysis}

In order to analyze the data we used inferential statistics. Therefore, we used one-sample T-test, one dimensional Kolmogrov-Smirnov test, the comparison between histogram and normal graphs and Friedman test. We used one sample T-test to test hypotheses, one dimensional Kolmogrov -Smirnov test and histogram and normal graphs to survey the hypothesis that data are normal and Friedman-test to prioritize the variables. It is worth to note that in each case before using one-sample T-test, we surveyed the supposed normal hypothesis.

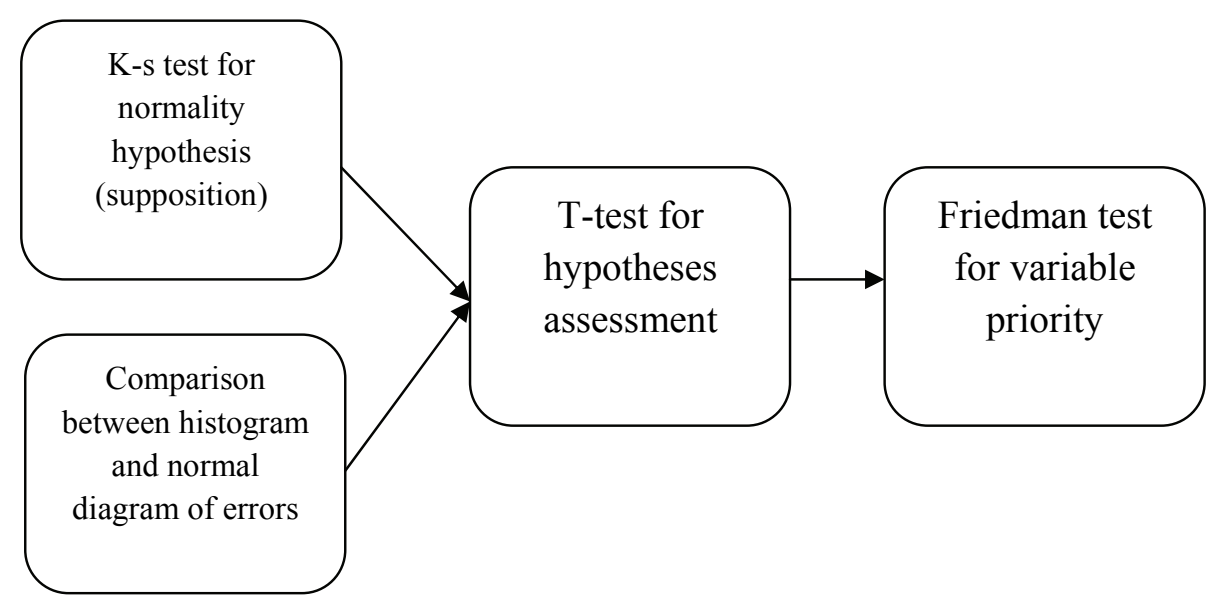

Fig. 2. Data analysis 


\subsection{Testing the hypotheses}

To analyze all the hypotheses we use the following method:

Hypothesis1: the propensity to outsource operations and activities exerts a positive influence on the operations objective "improved services".

A. Surveying to find out whether variable data of a service are normal or not.

Question: Do the gained data of the dependent variable have normal distribution?

The mathematical form is:

H0:The data have normal distribution

H1:The data don't have normal distribution

The results are:

Table 1

KOLMOGROV-SMIRNOV test results

\begin{tabular}{lll}
\hline Flexibility & & \\
\hline 97 & $\mathrm{~N}$ & \multirow{2}{*}{ Normal Parameters(a, b) } \\
3.1271 & Mean & \\
0.8214 & Std. Deviation & \multirow{2}{*}{ Most Extreme Differences } \\
0.0940 & Absolute & \\
0.0810 & Positive & \\
-0.0940 & Negative & \\
0.9250 & KOLMOGROV-SMIRNOV Z & \\
0.3590 & Asymp. Sig & \\
\hline
\end{tabular}

According to the results of Table 1 the meaningful level gained for $\mathrm{Z}$ one dimensional KOLMOGROV-SMIRNOV test is more than 0.05 . Therefore, in the confidence level of $\% 95$ there is no strong evidence to reject the null hypothesis, the null hypothesis is accepted and the variable's data have normal distribution. Therefore, the prerequisite, which is needed to use T-test exists.

This hypothesis includes six questions:

T-test:

Is the mean concerning the variable under the survey more than 3 ?

The mathematical form is:

$$
\left\{\begin{array}{l}
\mathbf{H}_{0}: \mu \leq 3 \\
\mathbf{H}_{1}: \mu>3
\end{array}\right.
$$

The corresponding table is:

The table concerning T-test is illustrated in Table 2.

Table 2

T-test results for improved service

\begin{tabular}{|c|c|c|c|c|c|c|c|c|}
\hline & & & & & $95 \% \mathrm{Lc}$ & & & \\
\hline Variable & $\mathrm{N}$ & Mean & StDev & SE Mean & Bound & $\mathrm{T}$ & $\mathrm{P}$ & Result \\
\hline SERVICE1 & 97 & 3.454 & 1.08 & 0.11 & 3.271 & 4.14 & 0.000 & $x>3$ \\
\hline SERVICE2 & 97 & 3.4948 & 0.9588 & 0.0973 & 3.3332 & 5.08 & 0.000 & $x>3$ \\
\hline SERVICE3 & 97 & 3.6186 & 0.9403 & 0.0955 & 3.46 & 6.48 & 0.000 & $x>3$ \\
\hline SERVICE4 & 97 & 3.423 & 1.079 & 0.11 & 3.241 & 3.86 & 0.000 & $x>3$ \\
\hline SERVICE5 & 97 & 3.144 & 1.061 & 0.108 & 2.965 & 1.344 & 0.092 & $X<3$ \\
\hline SERVICE6 & 97 & 2.948 & 1.061 & 0.099 & 2.782 & -0.52 & 0.697 & $X<3$ \\
\hline
\end{tabular}


For instance, for question number 1, the meaningful level, which is obtained for statistic $\mathrm{T}$ is less than 0.05 and also the amount of $\mathrm{T}$ is more than that of the table (2.045), so there are strong evidences to reject the null hypothesis; therefore the null hypothesis is rejected and the converse hypothesis is accepted. We use the same method in analyzing the rest of the questions. Table 3 summarizes the results of our t-test for all hypotheses.

\section{Table 3}

The details of the proposed survey results

\begin{tabular}{|c|c|c|c|c|}
\hline Hypothesis & Assymp & Sig & $\mathrm{T}$ value & decision \\
\hline $\begin{array}{l}\text { The propensity to outsource operations and activities exerts a } \\
\text { positive influence on the operations objective "cost reduction". }\end{array}$ & 0.000 & & 9.77 & approved \\
\hline $\begin{array}{l}\text { The propensity to outsource operations and activities exerts a } \\
\text { positive influence on the operations objective "improved } \\
\text { quality". }\end{array}$ & 0.000 & & 5.62 & approved \\
\hline $\begin{array}{l}\text { The propensity to outsource operations and activities exerts a } \\
\text { positive influence on the operations objective "flexibility". }\end{array}$ & 0.000 & & 7.03 & approved \\
\hline $\begin{array}{l}\text { The propensity to outsource operations and activities exerts a } \\
\text { positive influence on the operations objective "improved } \\
\text { service". }\end{array}$ & 0.000 & & 4.64 & approved \\
\hline $\begin{array}{l}\text { improved organizational function is directly related to } \\
\text { outsourcing. }\end{array}$ & 0.000 & $\begin{array}{l}6.30 \\
7.53\end{array}$ & $\begin{array}{l}\text { Financial } \\
\text { Performance } \\
\text { Non-Financial } \\
\text { Performance }\end{array}$ & approved \\
\hline
\end{tabular}

\subsection{Friedman-test}

We have used this test to prioritize the variables. In this method, in every column to each element is given an ascendant rank (number). In our survey to find out whether the means of " $\mathrm{K}$ " variables are equal with each other or not we first collect the responses and the results are compared to the amounts in the table and the conclusion is achieved concerning null hypothesis. Table 4 summarizes the results of our survey.

\section{Table 4}

The results of Friedman-test

\begin{tabular}{lcc}
\hline Variable & Mean Rank & Priority \\
\hline Cost Reduction & 4.14 & 1 \\
Improved Quality & 3.20 & 5 \\
Flexibility & 3.57 & 3 \\
Financial Performance & 3.70 & 2 \\
Non-Financial performance & 3.51 & 4 \\
Service & 2.89 & 6 \\
\hline
\end{tabular}

In our survey, the number of sample, Chi-Square are 97 and 27.025, which confirms the results of Friedman-test is meaningful under 5\% significance level. The priority of each variable with its correspondent rank is shown in the above Table 4.

\section{Conclusion}

In this paper, we have presented an empirical study to measure the impact of different items on increasing efficiency of a supply chain through outsourcing activities. The results of this survey indicated that outsourcing could lead to reduce cost, improve quality, increase flexibility, better 
financial and non-financial performance and services. In addition, we recommend the following comments and suggestions to improve the outsourcing as follows,

- Participation of the suppliers in designing and developing products,

- Making a friendly atmosphere with suppliers,

- Long-term relations with suppliers instead of multiple ones,

- Prioritizing activities in respect to the costs and entrusting according to hierarchy,

- Participating in the source-finding decisions with suppliers,

- Creating management teams of supplying network in order to embrace different companies,

- Qualitative evaluation of suppliers periodically,

- Entrusting activities which by entrusting them the company gains more flexibility,

- Entrusting important activities and processes concerning customers' opinions about suppliers,

- Enhancement of the company's power penetration in supplying network through placing trust among the members of the supplying network,

- Optimizing the geographical distance between customers and suppliers in the supplying network,

\section{Acknowledgements}

The authors thank the two anonymous reviewers for their contributions and comments on this paper.

\section{References}

Bardhan, A. D. \& Kroll, C. (2008). The New Wave of Outsourcing. University of California, Berkeley.

Kedia, B. L., \& Lahiri, S. (2007). International outsourcing of services: A partnership model. Journal of International Management, 13(1), 22-37.

Duncan, D.G., \& Groves-Rowan. T. (1997). Outsourcing and the bottom line. Mortgage Banking, 4856.

Frayer, J.K., J.D. Scannell, \& Thomas, W. (2000). An empirical investigation of global sourcing strategy effectiveness. Journal of Supply Chain Management, 36(2), 29-38.

White, H. S. (2000). Why outsourcing happens and what to do about it. American libraries, 31(1), 69.

Lau, R.S., \& Hurly, C.N. (1997). Outsourcing through strategic alliances. Management Journal, 38(2), 52-57.

Klaas, S.B., McGlendon, J.A., \& Gainey, T.W. (2001). Outsourcing HR: The impact of organizational characteristics. Human Resource Management, 40(2), 125-138.

Kotabe, M. (1998). Efficiency vs. effectiveness orientation of global sourcing strategy: A comparison of U.S. and Japanese multinational companies. Academy of Management Executive, 12(4), 107119.

Agrawal , M., Kishore, R., \& Rao, H.R. (2006). -Market reactions to E-business outsourcing announcements: An event study. Information \& Management, 43, 861-873.

Masaaki, K., Mol, M. J., \& Murray, J. Y. (2008). Outsourcing, performance, and the role of ecommerce: A dynamic perspective. Industrial Marketing Management, 37(1), 37-45.

Choi, M., Brand, M., \& Kim, J. (2008). A feasibility evaluation on the outsourcing of quality testing and inspection. International Journal of Project Management, 27(1), 89-95.

Belcourt, M. (2006). Outsourcing — The benefits and the risks. Human Resource Management Review, 16, 269-279.

Steensma, K.R., \& Corley, K.G. (2000). On the performance of technology-sourcing partnerships: The interaction between partner interdependence and technology attributes. Academy of Management Journal, 43(6), 1045-1067. 
Li, S., Ragu-Nathan, S.B., Rao, S., \& Ragu-Nathan, T.S. (2006).The impact of supply chain management practices on competitive advantage and organizational performance. OMEGA International Journal of Management Science, 34(2), 107-124.

Espino-Rodriguez, T. F., \& Padron-Robaina, V. (2004). Outsourcing and its impact on operational objectives and performance. Hospitality Management, 23, 287-306 